\title{
Longitudinal Changes in Water Quality to Landscape Gradients along Jialu River Basin
}

\author{
Teng Wen ${ }^{1, a}$ \\ ${ }^{1}$ School of Geography Sciences, Nanjing Normal University, Nanjing, P. R. China \\ awenteng@njnu.edu.cn
}

Keywords: Longitudinal scale, Response curve, Restoration, Stream ecosystem, Urban land

\begin{abstract}
Lateral and longitudinal scales are both critical to understand the response of stream ecosystem to landscape changes. The aim in this study was to investigate the characteristic reaches explaining water quality most along the longitudinal scale of Jialu River Basin, a highly polluted stream in China. Results showed that most deteriorated water quality were observed at headwater sites of Jialu River Basin where towns and cities intensely located. However, water quality were apparently improved along sites at middle or lower reaches. Urbanization is the primary cause, in spite of that the dominant land type in Jialu River Basin is agriculture. Additionally, the primary water pollution in Jialu River Basin is coming from the urban places located in headwater reaches. Overall,our results shows a case study by a model integrating framework which is helpful for achieving sustainable development in China.
\end{abstract}

\section{Introduction}

The degradation of streams and rivers, especially for those deteriorated by anthropogenic activity, has received increasing recognition as a global environmentall problem [1]. Although large amounts of researches focusing on the impacts of urbanization and agriculture on stream ecosystem, there are still many stream managers, especially in developing countries like China, still have difficulties in acknowledging the presence of a problem, not to mention solving it[2-4].

Streams or rivers are tightly connected with adjacent land area. The connection is generally composed by three different axes: the lateral axis connected channel and margins, the longitudinal axis connected upstream and downstream, and the vertical axis connected surficial and underground environments [5, 6]. Upon the three dimension structure, nutrients and energy are exchanged and transported laterally, longitudinally and vertically between stream ecosystem and its surroundings [1]. The lotic ecosystem respond to longitudinal scale environmental conditions is a fundamental paradigm in stream ecology [7]. It describes the longitudinal continuous changing of physical propertiesfrom headwater to mouth and the series of ecosystem responses to loading, transport, utilization and storage of nutrients and biota communities under natural or human-altered conditions[8]. For a natural stream ecosystem, the headwater sites is characterized by low nutrients load and diversity which are usually peaking in middle order reaches, and gradually declining downriver due to the uptake of some nutrients $[4,9]$. However, due to enoumous environmental factors induced by human such as agriculture intensity, and urbanization, most stream ecosystems only partially followed the prediction of longitudinal distribution of nutrients and will undoubtedly lead to the observable discrepancies with predictions under natural factors[10-13]. "Cumulative effect" is one of them. It describes the human-induced impacts happening within a drainage basin. Thes impacts often interact with natural processes and have increasing, summed, or interactive consequences downstream[1]. Some other studies further indicated that the cumulative effect was more frequently appeared in highly disturbed stream ecosystems, because many anthropogenic impacts are part of the larger process of catchment land use or land cover change that can deeply influence water quality and biota community[14-16].

Jialu River basin is a stream ecosystems having been seriously polluted by human activity. Due to the excessive economic development, the rapid urbanization and industrialization, the natural baseflow in Jialu River has been greatly diminished recently, instead of receiving massive discharge 
of urbanized and agricultural wastewater.The goal of this study was: i) to determine the relationship between water quality and urbanization along the longitudinal gradient in the polluted stream ecosystem; ii) to examine the degree to which water quality in the stream corresponding to the natural uptake predictions or cumulative effect.

\section{Methods}

Study area description. Jialu River lies within the Huai River Catchment, listed among the seven largest rivers in China. Jialu River is one of the most seriously polluted branches of Huai River[17]. It is $256 \mathrm{~km}$ long with basin area of 5,896 km² (Fig. 1).

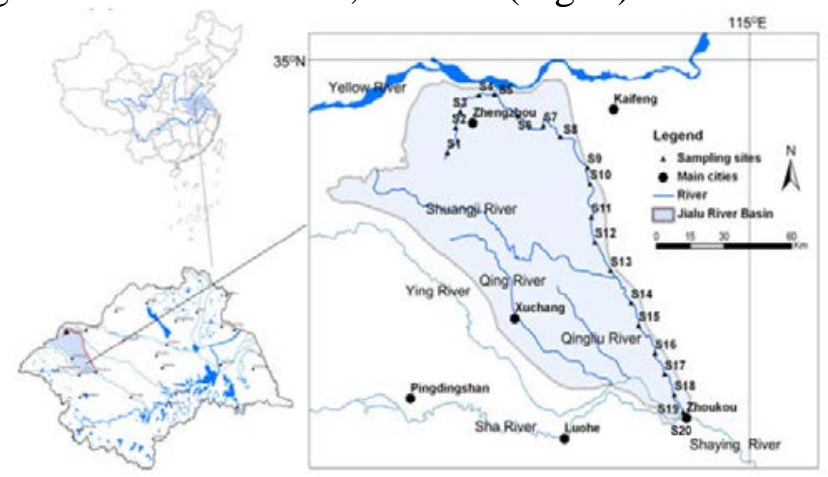

Fig. 1 Location of study area and sampling sites

Sampling and field surveys. The sampling and field surveys were performed in AugustSeptember of 2009 and 2011, a period with moderate temperatures and base flow conditions. The 20 sampling sites originally based on a probabilistic sampling design were shown in Fig. 1 . At these sampling sites, measures of water quality were conducted.

Statistic analysis. Sites were subjectively split into three groups: (1) headwater (sites 1-8); (2) mid-reach (sites 9-15); and (3) lower reaches (sites 16-20). Differences between sites were compared with a parameteric analysis of variance (ANOVA) and significant differences were accepted at $P<0.05$. Multivariate analysis of water quality was conducted by redundancy analysis (RDA) using Canoco 5.0.

\section{Results}

Land use. Within the $60 \mathrm{~m}$ buffer scale, agriculture was the dominant land use in Jialu River basin and accounted for beyond 50\% land area in most sampling reaches (Fig. 1). Compared with agriculture, urban land just covered a small percent of area along the $60 \mathrm{~m}$ longitudinal buffer. Moreover, from the headwater to the mouth, the distribution of urban land varied greatly among different sampling reaches. For example, at S1 located the headwater reaches of Jialu River, it was the only type of land use, and at S20, the last sampling site at the mouth, it covered nearly half of the land area. However, at S3, S4, S7, S13, S16 and S19, there was no urban land existing. Among the rest sampling reaches, the cover of urban land ranged from 3-20\%.

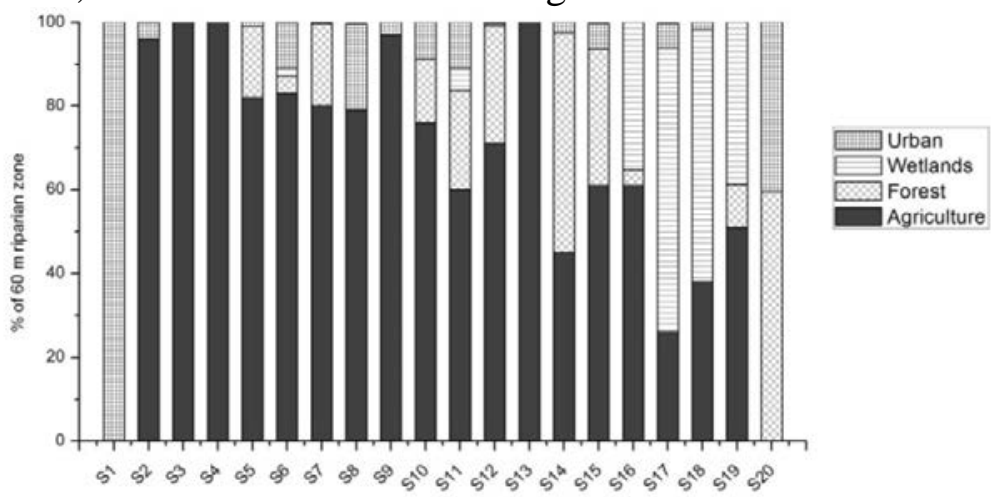

Fig. 2 The land cover composition distribution of each sampling reach within $60 \mathrm{~m}$ longitudinal buffer at Jialu River basin in 2008 
Water quality. As Fig. 2 showed, the whole Jialu River experienced serious water pollution but this condition of water quality was steadily mitigated downriver. Concentrations of $\mathrm{TN}, \mathrm{NH}_{3}-\mathrm{N}$ and $\mathrm{COD}_{\mathrm{Mn}}$ exhibited consistant difference from headwater to downriver, and they all varied significantly between headwater and lower reach sites $(P<0.001)$. Here, at the first headwater site (S1), the values of $\mathrm{TN}, \mathrm{NH}_{3}-\mathrm{N}$ and $\mathrm{COD}_{\mathrm{Mn}}$ were at the highest level, with $\mathrm{TN}$ beyond $16 \mathrm{mg} \mathrm{L}^{-1}$, $\mathrm{NH}_{3}-\mathrm{N}$ nearly $14 \mathrm{mg} \mathrm{L}^{-1}$, and $\mathrm{COD}_{\mathrm{Mn}}$ up to $75 \mathrm{mg} \mathrm{L}^{-1}$. All of the three values were about 6-15 times higher than the WHO and Chinese State Standard (CSS) max permissible limit for drinking water (TN: $2 \mathrm{mg} \mathrm{L}^{-1}, \mathrm{NH}_{3}-\mathrm{N}$ : $2 \mathrm{mg} \mathrm{L}^{-1}$, and $\mathrm{COD}_{\mathrm{Mn}}$ : $5 \mathrm{mg} \mathrm{L}^{-1}$ ). However, the three values were largely decreased at the second headwater sampling site (S2), and further reduced at the mid-reach sites. Although there were some fluctuations of $\mathrm{TN}, \mathrm{NH}_{3}-\mathrm{N}$ and $\mathrm{COD}_{\mathrm{Mn}}$, they were maintained at levels ranging from 10 to $12 \mathrm{mg} \mathrm{L}^{-1}$ in $\mathrm{TN}$, from 5 to $6 \mathrm{mg} \mathrm{L}^{-1}$ in $\mathrm{NH}_{3}-\mathrm{N}$, and from 7.4 to $26.8 \mathrm{mg}$ $\mathrm{L}^{-1}$ in $\mathrm{COD}_{\mathrm{Mn}}$. At the downstream sites, the values of the $\mathrm{TN}, \mathrm{NH}_{3}-\mathrm{N}$ and $\mathrm{COD}_{\mathrm{Mn}}$ were decreased to the lowest levels. However, even so greatly reduce of the three values, they were still not achieved the max allowable standard limit for drinking water in China.

The variations of TP along Jialu River were largely mirrored the trends of $\mathrm{TN}, \mathrm{NH}_{3}-\mathrm{N}$ and $\mathrm{COD}_{\mathrm{Mn}}$. The highest level of TP was also observed at the headwater reaches, but was in S2 site $\left(0.76 \mathrm{mg} \mathrm{L}^{-1}\right)$. Then, TP concentrations were nearly cut in half at the mid-reach of Jialu River (ranging from 0.43 to $0.45 \mathrm{mg} \mathrm{L}^{-1}$ ). At the end of mid-reach, the values of TP were raised up to 0.58 $\mathrm{mg} \mathrm{L}^{-1}$, but it was decreased again at the lower reaches. The lowest TP concentrations occurred at the sites of lower reaches, about $0.42 \mathrm{mg} \mathrm{L}^{-1}$.

RDA results. Fig. 4 illustrated the ordination diagram between the water quality and landscape variables. The first axis consistently represented the gradients of nearly all water quality variables, while the second axis only displayed the values of water transparency. Urban land was the dominant predictor for water quality values at the first axis. It was positively correlated with TN, NH3-N, TP, PO4-P, and CODMn but negatively associated with $\mathrm{pH}$ and NO3-N. In addition, the RDA results separated the water quality variables into distinct clusters of headwater, mid-reach and lower reach. When sampling sites were projected onto the water quality variables, the sampling sites at headwater had the higher values of TN, NH3-N, TP, PO4-P, and CODMn, especially the S1 site whose values was the highest. Then, the mid-reach sampling sites were predicted to have lower values. Yet, for the sampling sites located at lower reach, the expected values of TN, NH3-N, TP, PO4-P, and CODMn decreases even more greatly than the mid-reach sites.
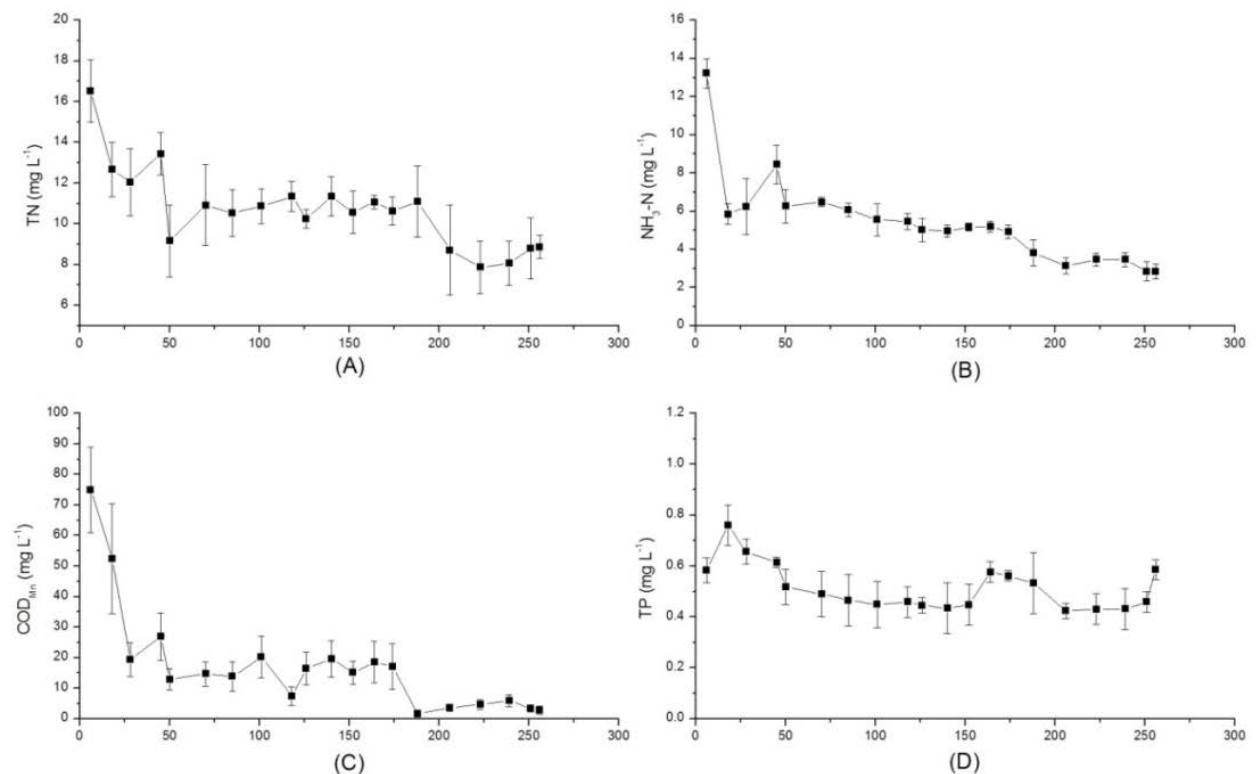

Fig.3 Mean concentrations of $\mathrm{TN}, \mathrm{NH}_{3}-\mathrm{N}, \mathrm{COD}_{\mathrm{Mn}}$, and $\mathrm{TP}$ at each of the nineteen sampling sites along the length of Jialu River $(n=3, \pm 1 S E)$ 


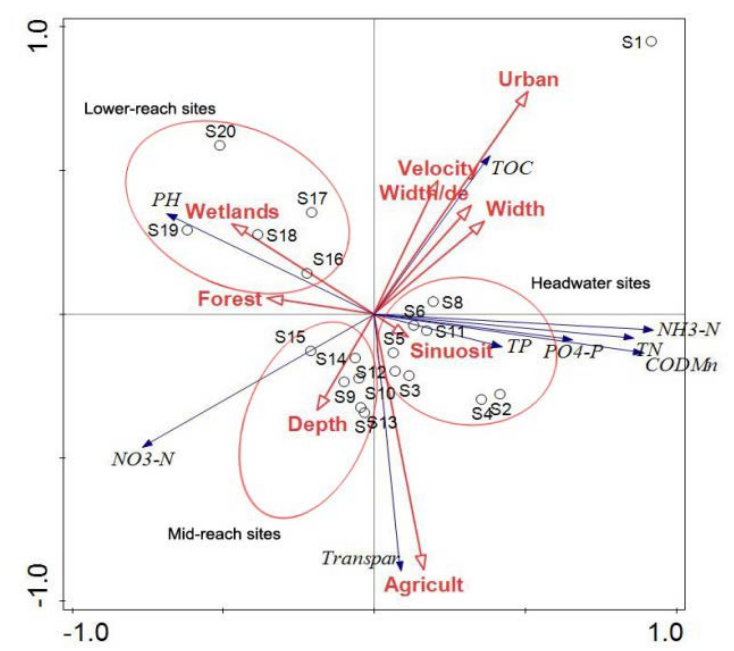

Fig. 4 Redundancy analysis for water quality plotted against land use and physic-hydrological parameters at each site within $60 \mathrm{~m}$ buffer scale: headwater (sites 1-8); mid-reach (sites 9-15) and lower reaches (sites 16-20).

\section{Discussion}

The recent two decades have been turbulent ones for Henan province's urbanization. Radical changes in Government policy towards urbanization expanding have necessitated major reforms in land use change. The Jialu River basin typifies these province-wide trends. Within the catchment, many urban centers developed around stream, which were lifeblood of commerce. Consequently, cities or villages intensity has increased over these ten years, particularly in the upper and lower reaches of the stream. As we know, this extensive and ever-increasing urbanization leads to a threat to stream ecosystem[18]. The results confirmed our prediction that urban land was the primary factor to explain the deterioration of water quality. Yet, in Jialu River basin, the total urban land covers no more than $10 \%$ land area at the catchment scale, not to mention its null distribution at some sampling reaches within the $60 \mathrm{~m}$ buffer scale. Even though the area covered by urban land is minor in comparison to agricultural area, it has similarly or worse devastating effects on stream water quality. Wear et al. [19] have suggested that the most remote portion of the watershed and the outer edge of urban development have disproportionate influences on water quality. In general, some other researchers[20,21] also suggested that once urban land use goes up beyond a 5\% of total land cover (the precise amount requires further research), then urban land use impacts on water quality dominate over agricultural impacts[22].

In Jialu River basin, the levels of water nutrients were gradually reduced from headwater to downstream, where the distribution of urban land differed. Urban land area was highest at the first headwater sampling sites, and even achieved to 50\% at the last sampling site downstream. As we known, the lotic ecosystem has the ability of self-purification, a natural process by which streams maintain their pristine condition in response to the introduction of foreign matter, such as remove "polluting" levels of phosphorus and nitrogen nutrients[23]. Thus some studies concluded that the nutrients tend to decrease downstream[2, 21]. However, overloading or saturation of this buffer capacity of stream will undoubtedly lead to breakthrough of nutrients and enrichment downstream. Several studies confirmed this kind of human induced cumulative impacts in stream ecosystem. Jialu River basin is a drainage undergoing huge human disturbance and overloading pollutants. Its water nutrients levels are far beyond the permission limits for drinking water, and in-stream invertebrates are dominated by highly pollution-tolerated species. We therefore assumed its "self-purification" capacity should have been reduced or destroyed, and cumulative effect should have been aggregated downstream. However, things are totally out of our exception. The gradually dramatic decrease of pollution nutrients downstream was exactly the "self-purification" process. The decrease of ammonium downstream was accompanied withthe increase of nitrate, indicating the strong nitrification process and related bacteria activity. Noted this, we have to admit, even in 
such a highly disturbed and seriously polluted stream, the function of lotic ecosystem was still operated normally. The most reasonable explanation for this phenomenon is what Folke et al. [24] called resilience, which helps Jialu River basin to absorb disturbance and remain within the same regime that essentially retains the same function, structure and feedbacks.

\section{Reference}

[1] J.D. Allan, Influence of land use and landscape setting on the ecological status of rivers, Limnetica 23(2004) 187-198.

[2] P.S. Lake, N. Bond and P. Reich, Linking ecological theory with stream restoration, Freshwater Biol. 52(2007) 597-615.

[3] M. Lammert and J.D. Allan, Assessing biotic integrity of streams: effects of scale in measuring the influence of land use/cover and habitat structure on fish and macroinvertebrates, Environ. Manage. 23(1999) 257-270.

[4] J.D. Allan and M.M. Castillo. Stream ecology: structure and function of running waters. Springer Science \& Business Media, 2007.

[5] C. Koç, A study on the pollution and water quality modeling of the River Buyuk Menderes, Turkey, Clean-Soil Air Water. 38(2010) 1169-1176.

[6] H. Piégay and S.A. Schumm, System approaches in fluvial geomorphology, Tools fluv. geomorphol.(2003) 103-134.

[7] R.J. Naiman and M.G. Turner, A future perspective on North America's freshwater ecosystems, Ecol. Appl. 10(2000) 958-970.

[8] J. Harding, E. Benfield, P. Bolstad, G. Helfman and E. Jones, Stream biodiversity: the ghost of land use past, P. Natl. Acad. Sci. USA. 95(1998) 14843-14847.

[9] R.L. Vannote, G.W. Minshall, K.W. Cummins, J.R. Sedell and C.E. Cushing, The river continuum concept, Can. J. Fish Aquat. SCI. 37(1980) 130-137.

[10]A. Larrañaga, A. Basaguren, A. Elosegi and J. Pozo, Impacts of Eucalyptus globulus plantations on Atlantic streams: changes in invertebrate density and shredder traits, Fund. Appl. Limnol. 175(2009) 151-160.

[11]M.D. Delong and M.A. Brusven, Macroinvertebrate community structure along the longitudinal gradient of an agriculturally impacted stream, Environ. Manage. 22(1998) 445-457.

[12]K.A. Martell, A.L. Foote and S.G. Cumming, Riparian disturbance due to beavers (Castor canadensis) in Alberta's boreal mixedwood forests: implications for forest management, Ecoscience 13(2006) 164-171.

[13]S. Tomanova, N. Moya and T. Oberdorff, Using macroinvertebrate biological traits for assessing biotic integrity of neotropical streams, River Res. Appl. 24(2008) 1230-1239.

[14]P.V. Bolstad and W.T. Swank, Cumulative impacts of landuse on water quality in a southern Appalachian water shed, J. Am. Water Resour. As. 33(1997) 519-533.

[15]A. Baker, Land use and water quality, Encyclopedia of Hydrological Sciences. 2005pp. 1-6.

[16]C. Hudon and R. Carignan, Cumulative impacts of hydrology and human activities on water quality in the St. Lawrence River (Lake Saint-Pierre, Quebec, Canada), Can. J. Fish Aquat. 65(2008) 1165-1180.

[17]C. Wang, Y. Wang, Z. Mo and Z. Wang, Ecotoxicological examination of sediment extracts of Huaihe River, China by in vitro bioassays, B. Environ. Contam. Tox. 71(2003) 782-790. 
[18]D. Von Schiller, E. Marti, J.L. Riera, M. Ribot, J.C. Marks and F. Sabater, Influence of land use on stream ecosystem function in a Mediterranean catchment, Freshwater Biol. 53(2008) 2600-2612.

[19]D.N. Wear, M.G. Turner and R.J. Naiman, Land cover along an urban-rural gradient: implications for water quality, Ecol. Appl. 8(1998) 619-630.

[20]M.J. Paul and J.L. Meyer, Streams in the urban landscape, Annu. Rev. Ecol. Syst. 32 (2001) 333-365.

[21] M. House, J. Ellis and R. Shutes, Urban rivers: ecological impact and management, Urban Waters. Regen. (1993) 312-322.

[22]R. Costanza and C. Folke, Valuing ecosystem services with efficiency, fairness, and sustainability as goals, Nature's services: societal dependence on natural ecosystems. Island Press, Washington, DC,1997, pp. 49-70.

[23]A. Vaideliene and N. Michailov. Dam influence on the river self-purification. in Proc. of the 7th International Conference "Environmental Engineering (2008)

[24]C. Folke, Resilience: The emergence of a perspective for social-ecological systems analyses, Global Environ. change 16(2006) 253-267. 